\title{
First Metatarsal Artery Capillary Perforator Flaps
}

Isao Koshima, MD*; Hirofumi Imai, MD'; Shuhei Yoshida, MD; Mitsunaga Narushima, MD²;

Shuji Yamashita MD³, Takuya lida, MD³

1 International Center for Lymphedema, Hiroshima University Hospital, Hiroshima, Japan

2 Department of Plastic and Reconstructive Surgery, Mie University Hospital, Mie, Japan

${ }^{3}$ Department of Plastic and Reconstructive Surgery, University of Tokyo, Tokyo, Japan

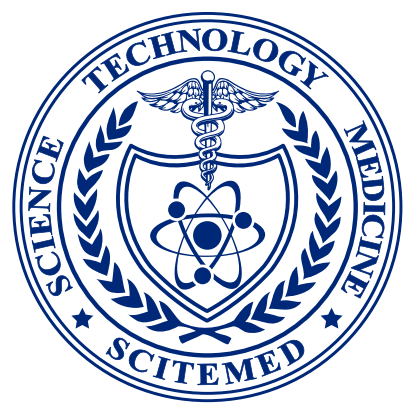

\begin{abstract}

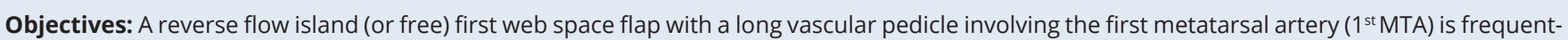
ly used for the coverage of toes and finger defects. The major disadvantages of this flap are postoperative donor site pain and numbness due to damage to the deep peroneal nerve, or depressive scarring on the first web space following soft tissue loss.

Methods: Instead of the dominant perforators of perforator flaps, capillary perforators are recently becoming a new pedicle vessel of perforator flaps. Therefore, to overcome these disadvantages of the first web space flap, the first metatarsal artery capillary perforator (1 ${ }^{\text {st }}$ MTAcp) flap with a capillary perforator was used as island and free flaps. Since 1994, eight patients with foot and hand defects were treated with five island and three free $1^{\text {st }}$ MTAcp flaps.

Results: There were no flap necrosis and no problems due to nerve compression in the donor site. It was found that a free $1^{\text {st }}$ MTAcp flap, including a short "T" segment of the $1^{\text {st }}$ MTA, was useful as a flow-through flap for finger pulp defects.

Conclusion: An island or free $1^{\text {st }}$ MTAcp flap is possible without including the $1^{\text {st }}$ MTA. The advantages of this flap include the preservation of the first metatarsal artery (in case of an island flap) and the adiposal tissue in the web space, which prevent compression around the remaining deep peroneal nerve. This results in no postoperative donor site pain or numbness due to damage to the deep peroneal nerve. There is no possibility of a depressive scar on the first web space because the soft tissue can be preserved in the donor site. The major disadvantage of this flap is that since the perforators are so small (sometimes invisible), loops or operative microscope are required for their dissection. This flap is indicated for the great and second toes as an island flap, and for hand and fingers as a free flap.
\end{abstract}

\section{Introduction}

A free first web space flap with a long vascular pedicle involving the first metatarsal artery ( $\left.1^{\text {st }} \mathrm{MTA}\right)$ is used for the coverage of toe and finger defects as a reverse-flow island or free flap [1-3]. The major disadvantages of this flap are postoperative donor site pain, numbness due to damage to the deep peroneal nerve, and a depressive scar on the first web space following soft tissue loss. Meanwhile, instead of the dominant perforators of perforator flaps, capillary perforators are recently becoming more widely used as a common new pedicle vessel of perforator flaps $[4,5]$. As the $1^{\text {st }}$ MTA had several capillary perforators, a new less invasive island flap, the first metatarsal artery capillary perforator (1 $1^{\text {st }}$ MTAcp) flap, was installed without sacrificing the $1^{\text {st }}$ MTA or the soft tissue in the first web space. In addition, it was found that a free $1^{\text {st }}$ MTAcp flap, including a

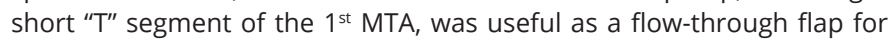
palm defects of the hand. In this series, we report an island capillary perforator flap without transection of the $1^{\text {st }}$ MTA and a free flap with a short segmental $1^{\text {st }}$ MTA.

\section{Methods}

\section{Anatomy of the First Metatarsal Artery}

The $1^{\text {st }}$ MTA comes from the dorsalis pedis artery and connects to the proper digital arteries of the great and second toes with the communicating branch. This communicating branch is usually large and connects directly to the digital arteries. However, sometimes it is hypoplastic or missing (and the $1^{\text {st }}$ MTA distributes so as to terminate in the subcutaneous tissue of the first web space). The dominant communicating branch can be used as an island reverse flow $1^{\text {st }}$ MTA flap, including the $1^{\text {st }}$ MTA. The $1^{\text {st }}$ MTA usually has several capillary perforators. Anatomically, two types of capillary perforators exist: one is the superfascial adiposal perforator, which arises from the $1^{\text {st }}$ MTA which runs suprafascially. The other is the intermuscular type perforator, which arises from the intramuscular $1^{\text {st }}$ MTA, penetrating the interosseous muscle. The dorsal cutaneous veins, subdermal cutaneous veins, and several distal branches compose the superficial axial venous system through the $1^{\text {st }}$ MTA of the first web space. The deep peroneal nerve runs through the dorsalis pedis vessels and terminates in several branches on the first web space and the dorsal aspect of the great and second toes (Figure 1A).

\section{Surgical Techniques}

Using an air tourniquet (a tourniquet is very important to detect small perforators), a longitudinal incision was made on the first web space. Superficial subdermal and deep cutaneous veins were preserved as a drainage system of this flap. Several perforators penetrating through the interosseous muscle from the $1^{\text {st }}$ MTA and concomitant vein are usually detected under loops or operative microscopy. Including the main capillary perforator of the $1^{\text {st }}$ MTA, the flap was designed on the $1^{\text {st }}$ web space, sometimes extending into the proximal dorsum of the foot.

After a skin incision through the flap margin, the island flap is elevated from the proximal side of the dorsal foot. The perforators nearest to the defect, which are deeply dissected from the surrounding adiposal tissue, are confirmed to be connected to the cutaneous venous system. In cases in which the defects are in the great or second toe, the deep dissection or transection of the $1^{\text {st }}$ MTA is usually unnecessary because an island flap with a short pedicle can be rotated 180 degrees around the perforator to reach the defect. The branches of the deep peroneal nerve can also be preserved without any damage. Based on our cases, a single capillary perforator is enough to supply a flap, and a larger flap over $3 \mathrm{~cm}$ in width usually needs a skin graft to close the donor defect. In cases with hand pulp or palm defect, a short segment of the first metatarsal artery involving a perforator is interposed into the transected digital artery in a flow-through manner. The dorsal cutaneous vein and a branch of the deep peroneal nerve are also included as another pedicle (Figure 1B).

\section{Results}

Between June 1994 and December 2005, eight patients with extremity defects were treated with five island $1^{\text {st }}$ MTAcp flaps and three free $1^{\text {st }}$ MTA flaps. The number of defects was three in the fingers and hand, and five in the foot and toes. The operated patients were four males and four females with the age range of 12 to 75 years. The flaps ranged from 3 to $8 \mathrm{~cm}$ in length and 1 to $5 \mathrm{~cm}$ in width. As for postoperative complications, there were no serious complications and not any flap necrosis (Table 1). 

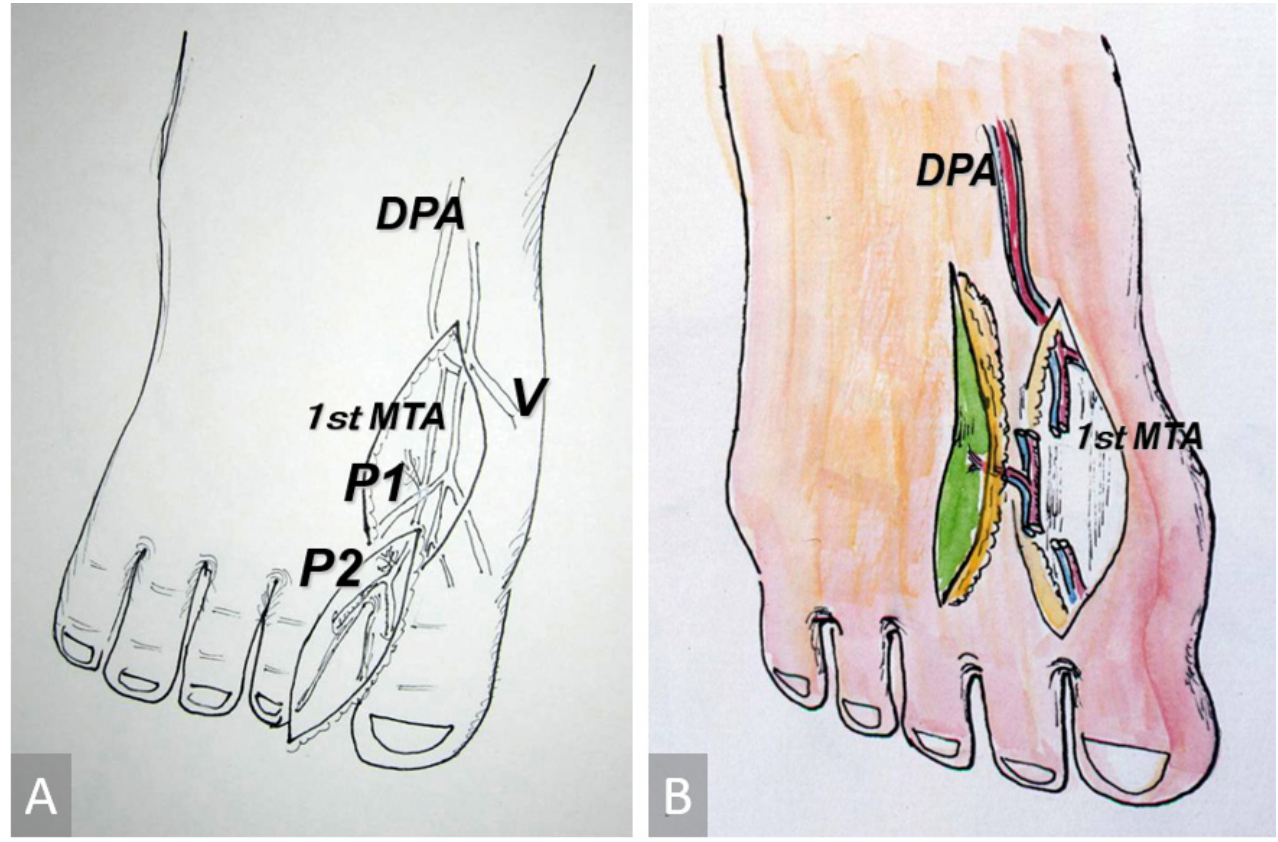

Figure 1. (A) Schematic drawing of the $1^{\text {st }}$ MTAcp flap. Small capillary perforators (P1 \& P2) arise from the first metatarsal artery at the first web space. (B) Free $1^{\text {st }}$ MTAcp flap with a short segmental vessel. $1^{\text {st }}$ MTAcp, first metatarsal artery capillary perforator; DPA, dorsalis pedis artery; $\mathrm{V}$, cutaneous vein.

\begin{tabular}{|c|c|c|c|c|c|c|}
\hline No. & Age & Sex & Defect & Flap & Flap Size $(\mathrm{cm})$ & Complications \\
\hline 1 & 56 & M & Great toe & Island $1^{\text {st }}$ MTAcp flap & $6 \times 3$ & None \\
\hline 2 & 12 & $\mathrm{~F}$ & Foot & Island $1^{\text {st }}$ MTAcp flap & $3 \times 1$ & None \\
\hline 3 & 53 & $\mathrm{~F}$ & Hand & Free $1^{\text {st }}$ MAPcp flap-DIP joint & $3 \times 1$ & None \\
\hline 4 & 26 & M & Second toe & Island $1^{\text {st }}$ MTAcp flap & $8 \times 2$ & None \\
\hline 5 & 75 & $\mathrm{~F}$ & Second Toe & Island & $7 \times 3$ & None \\
\hline 6 & 67 & M & Great toe & Island & $4 \times 1$ & None \\
\hline 7 & 16 & $\mathrm{~F}$ & Finger & Free $1^{\text {st }}$ MAPcp flap & $3 \times 1.5$ & None \\
\hline 8 & 59 & M & Hand & Free $1^{\text {st }}$ MAPcp flap & $8 \times 5$ & None \\
\hline
\end{tabular}

$1^{\text {st }}$ MTAcp, first metatarsal artery capillary perforator; DIP, distal interphalangeal joints; F, female; M, male.

\section{Case 1: Island Flap for Second Toe Defect (No. 4 in Table 1)}

A 26-year-old man sustained a skin necrosis on the volar side of the right second toe. This was caused by an avulsion injury and an X-ray revealed dislocation of the distal interphalangeal joint. After the resection of the necrotic tissue and repositioning of the distal phalangeal bone, an island $1^{\text {st }}$ MTAcp flap of $8 \times 2 \mathrm{~cm}$ was transferred to cover the defect. The donor defect was closed with a split-thickness skin graft from the right thigh. Postoperatively, the flap and skin graft survived completely, and the patient walked without problems (Figure 2).

\section{Case 2: Scar Related Contracture of the Little Finger (No. 8 in Table 1)}

A 59-year-old man sustained a skin defect on the volar aspect of the left little finger. This was combined with a complicated fracture of the fifth metacarpal phalanx by an encounter with a rice harvesting machine. Although an island ulnar artery perforator flap was used to repair the defect, a severe volar scar contracture of the little and ring fingers remained. After releasing the contracture, a free $1^{\text {st }}$ MTAcp flap of $8 \times 5 \mathrm{~cm}$, with a short segmental pedicle, was transferred. A short segment of the $1^{\text {st }}$ MTA and the dorsal cutaneous vein of the flap were anastomosed to the ulnar digital artery of the ring finger and the dorsal cutaneous vein of the hand. Postoperatively, the flap survived completely. The contracture of the little finger was released and there was not any donor site morbidity (Figure 3).

\section{Discussion}

In this series, we report an island capillary perforator flap without transection of the $1^{\text {st }}$ MTA and a free flap with a short segmental $1^{\text {st }}$ MTA. These flaps are completely different from the first web space flap, including the pedicle of the $1^{\text {st }}$ MTA. In 1989, Earley reported the first web flap with such capillary perforators and described the distal web-space cutaneous vessels, which arose from the $1^{\text {st }}$ dorsal MTA and common digital vessels [2]. The number of vessels with a diameter sometimes smaller than $0.3 \mathrm{~mm}$ varied between two and five arterial branches. However, the flap was not an island flap, but a rectangular flap based on wide skin pedicle including many pedicle vessels and nerves.

In this series, it was proved that only single perforators can feed the flap (maximum dimension $8 \times 5 \mathrm{~cm}$ ) with complete island elevation by transection of whole skin margin. Therefore, being differentiated from the conventional $1^{\text {st }}$ web flap or $1^{\text {st }}$ MTA flap reported by Earley, our flap was named as "1 1 st MTA capillary perforator flap".

The new concept of "capillary perforator flap" has been already proposed many times in the meetings of the International Perforator Course, World Society of Reconstructive Microsurgery, American Society of Reconstructive Microsurgery, and also described as "thoracodorsal artery capillary perforator (TAPCp) flap [5]." We defined "capillary perforator" as less than $0.3 \mathrm{~mm}$ perforator (sometimes invisible perforator with bare 

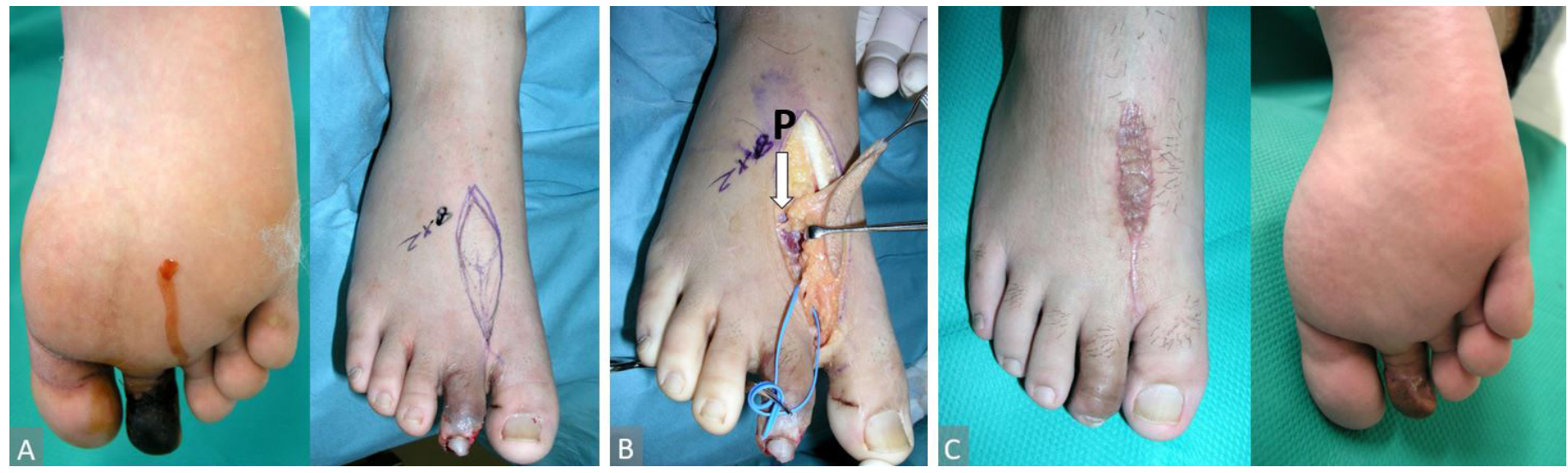

Figure 2. (A) Left, a 26-year-old man with volar skin necrosis of the right second toe. Right, an island $1^{\text {st }}$ MTAcp flap was designed. (B) The flap was transferred with the distal capillary perforator. P indicates transected proximal perforator. (C) Left, two months after surgery. The donor defect was closed with a split thickness skin graft. Right, the flap survived completely.
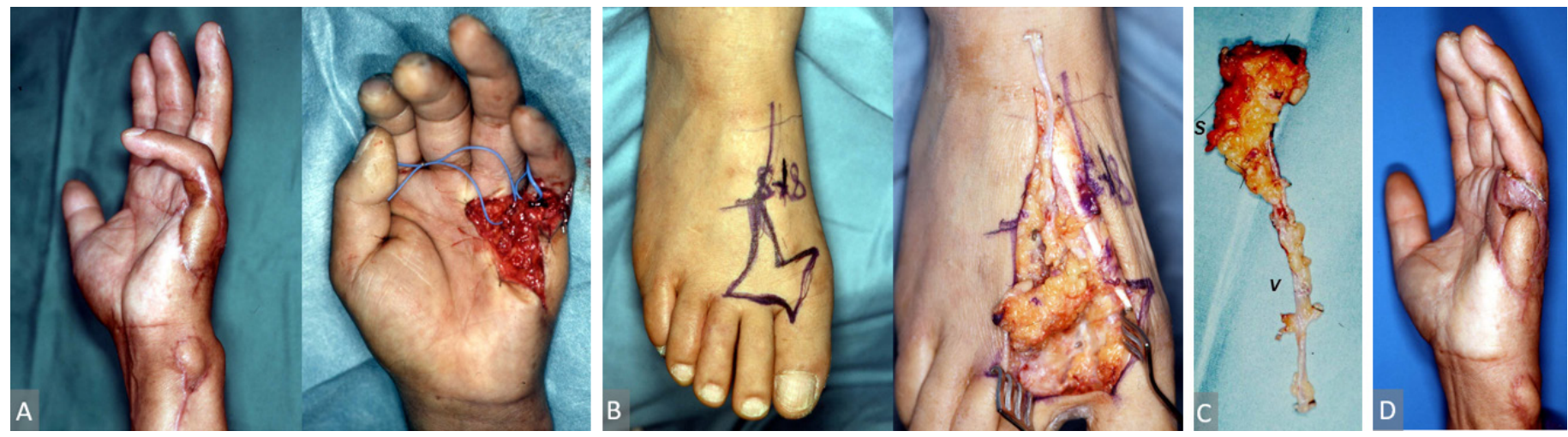

Figure 3. (A) Case 3, a 59-year-old man with a severe volar scar contracture of the left little finger. Right, the contracture was released. (B) A free flap with a short segment of $1^{\text {st }}$ MTA was elevated on the right foot dorsum. Left, flap design. Right, the deep peroneal nerve was preserved. (C) A short segment (marked as S) of the $1^{\text {st }}$ MTA and dorsal cutaneous vein (marked as V) of the flap were included in the flap and anastomosed to the ulnar digital artery of the ring finger and dorsal cutaneous vein of the hand. (D) Three months after surgery. The flap survived completely. $1^{\text {st }}$ MTA, first metatarsal artery.

eyes) and nourished skin flaps of some dimension (at least $7 \times 5 \mathrm{~cm}$ ). This concept is very important because recently, and in future, we believe that many new flaps nourished with much smaller perforators less than 0.3 $\mathrm{mm}$ are (and will be) proposed in some proper areas (around joints and through peripheral nerves) in the human body.

The advantages of this flap are that the $1^{\text {st }}$ MTA (in case of an island flap) and the deep peroneal nerve with the surrounding adiposal tissue can be preserved in the web space. There is no postoperative donor site pain or numbness. There is no possibility of a depressive scar on the first web space because the soft tissue can be preserved in the donor site. The disadvantages are that since the perforators are so small (sometimes invisible), loops are required for their dissection, and a large flap cannot be obtained without skin grafting onto the donor defect because of the tightness of the skin.

This flap is indicated for the coverage of the defects around the first web space, including the great and second toes as an island flap. As a free flap, with a short segment of the $1^{\text {st }}$ MTA and its perforator (flow-through flap), the defects of the hand and fingers can be repaired less invasively. In addition, free composite flaps including tendons, nerves, and/or joints can be used for composite hand defects. A simple vascularized deep peroneal nerve flap with the same pedicle is also useful for nerve defects in scarred beds.

In terms of future applications of this flap, based on our experience, a vascularized lymphadiposal flap is useful for severe lymphedema of the contralateral leg because some lymphatics with drainage function exist in the first web space of the leg [6]. There is no possibility of postoperative edema of the donor leg because of no damage of lymphatic system at the proximal leg, and each channel has rich vascular supply because of these perforators.

\section{Conclusion}

The $1^{\text {st }}$ MTAcp flap is a new capillary perforator flap and less invasive reconstructions with this flap are now possible for the defects around the first web space, toes, and fingers. In addition, the concept of the use of this capillary perforator flap will help open a new field in reconstructive surgery in the future.

\section{Article Information}

* Correspondence: Isao Koshima, MD

International Center for Lymphedema, Hiroshima University Hospital, 1-2-3, Kasumi, Minami-ku, Hiroshima City, 734-8551, Japan.

E-mail: koushimaipla@gmail.com

Received: Oct. 07, 2018; Accepted: Nov. 26, 2018; Published: Jan. 04, 2019

\section{DOI: 10.24983/scitemed.imj.2019.00093}

Copyright $(2019$ The Author (s). This is an open-access article distributed under the terms of the Creative Commons Attribution 4.0 International License (CC-BY).

Funding: None 


\section{Conflict of Interest: None}

\section{Acknowledgements}

The authors would like to thank Dr. Motoyuki Doi, Orthopedic Surgery in Kyokuto Hospital in Okayama City, and Dr. Masayuki Ohmori, Ohmori Clinic in Okayama City, for their supports of this work.

\section{Disclosures}

This work was presented in part at the Third International Course on Perforator Flap in Munich, on November 13, 1999, the 48th Japanese Society of plastic and Reconstructive Surgery in Tokyo, on April 13, 2005, and the 9th International Course on Perforator Flaps in Barcelona, on October 7, 2005.

\section{Informed Consent}

Informed consent were obtained from the patients.

\section{Keywords}

Capillary perforator; first metatarsal artery flap; foot; perforator flap; reverse flow flap; skin defect; supermicrosurgery.

\section{References}

1. Ishikawa K, Isshiki N, Suzuki S, Shimamura S. Distally based dorsalis pedis island flap for coverage of the distal portion of the foot. Brit J Plast Surg 1986;40(5):521-525.

2. Earley MJ, Milner RH. A distally based first web flap in the foot. BritJ Plast Surg 1989;42(5):507-511.

3. Satoh K, Kaieda K. Resurfacing the distal part of the foot with a dorsal foot skin island flap pedicled on the plantar vasculature. Plast Reconstr Surg 1995;95(1):177-180.

4. Koshima I, Narushima M, Mihara M, et al. Island medial plantar artery perforator flap for reconstruction of plantar defects. Ann Plast Surg 2007;59(5):558-562.

5. Koshima I, Narushma M, Mihara M, et al. New thoracodorsal artery perforator (TAPCP) flap with capillary perforators for reconstruction of upper limb. J Plast Reconstr Aesthet Surg 2010;63(1):140-145.

6. Koshima I, Narushima M, Mihara M, et al. Lymphadiposal flaps and lymphaticovenular anastomoses for severe leg edema: functional reconstruction for lymph drainage system. J Reconstr Microsurg 2016;32(1):50-55. 